\title{
A review of energy-efficient scheduling in intelligent production systems
}

\author{
Kaizhou Gao $^{1,2} \cdot$ Yun Huang ${ }^{1} \cdot$ Ali Sadollah $^{3} \cdot$ Ling Wang $^{4}$
}

Received: 12 July 2019 / Accepted: 30 August 2019 / Published online: 10 September 2019

(c) The Author(s) 2019

\begin{abstract}
Recently, many manufacturing enterprises pay closer attention to energy efficiency due to increasing energy cost and environmental awareness. Energy-efficient scheduling of production systems is an effective way to improve energy efficiency and to reduce energy cost. During the past 10 years, a large amount of literature has been published about energy-efficient scheduling, in which more than 50\% employed swarm intelligence and evolutionary algorithms to solve the complex scheduling problems. This paper aims to provide a comprehensive literature review of production scheduling for intelligent manufacturing systems with the energy-related constraints and objectives. The main goals are to summarize, analyze, discuss, and synthesize the existing achievements, current research status, and ongoing studies, and to give useful insight into future research, especially intelligent strategies for solving the energy-efficient scheduling problems. The scope of this review is focused on the journal publications of the Web of Science database. The energy efficiency-related publications are classified and analyzed according to five criteria. Then, the research trends of energy efficiency are discussed. Finally, some directions are pointed out for future studies.
\end{abstract}

Keywords Production scheduling $\cdot$ Energy efficiency $\cdot$ Swarm intelligence $\cdot$ Evolutionary algorithm

\section{Introduction}

Energy consumption is an important issue in current society. In last 40 years, the energy demand of the world has doubled and will double again in next 10 years [1]. In general, the industry is one of the primary consumers of energy. In 2018,

Ling Wang

wangling@tsinghua.edu.cn

Kaizhou Gao

kzgao@must.edu.mo

Yun Huang

yuhuang@must.edu.mo

Ali Sadollah

ali_sadollah@yahoo.com

1 Macau Institute of Systems Engineering, School of Business, Macau University of Science and Technology, Macau, China

2 School of Computer, Liaocheng University, Liaocheng, China

3 Department of Mechanical Engineering, University of Science and Culture, Tehran, Iran

4 Department of Automation, Tsinghua University, Beijing, China industry accounted for approximately $25 \%$ of energy consumption by end use in the European Union [2]. The energy consumption of industrial fields is about $26.3 \%$ of estimated U.S. energy consumption of 2018 [3]. As energy-intensive fields, manufacturing industries consumed nearly a third of the global energy consumption of the world [4, 5]. In China, more than $56 \%$ of the total energy consumption is occupied in manufacturing sector attributed [6].

It is essential to reduce the manufacturing industry's energy consumption and demand. The manufacturing industries play a key role to satisfy continuously growing of various goods as living standards increasing. It is unrealistic to reduce the energy supply for manufacturing industries directly, since energy is a non-substitutable production factor. In other words, it is limited to a certain extent to reduce energy consumption and to subject to the desired output simultaneously. Hence, how to improve energy efficiency or to reduce energy demands for the same output becomes a critical approach to achieve the purpose of reducing energy consumption and developing sustainably. It is a consensus in academic and business that "energy-efficiency gap" is a strong barrier which hinders energy-efficient manufacturing. 
In manufacturing shops, the energy consumption is noticeable. In actual machining processes, machine tools stay in an idle state for the most of the time and consume about $80 \%$ energy with the idle state [7]. Machine tools have huge potential space for energy saving [8]. In general, scheduling is an effective approach to solve the issues about machine status and is an important decision-making process to decide which tasks to execute, when to execute them, and where to process them in which sequence. It is rarely considered as a suitable instrument to improve energy efficiency. In recent years, many researchers use scheduling approaches to improve energy efficiency in manufacturing industries and energy-efficient scheduling has been proved to be an effective way of reducing the energy consumption with none or little capital investment [9, 10]. Energy efficiency or energy consumption is considered as constraints or scheduling objectives, like makespan, machine workload, and due-date objectives.

Production scheduling has been proven as an NP-hard problem; hence, energy-efficiency scheduling is no exception. Traditional optimization approaches cannot solve largescale scheduling problems with high efficiency, especially for some large-scale instances with real-time constraints. Therefore, swarm intelligence and evolutionary algorithms are employed for solving such problems as reported in many publications, since low computational time and high efficiency are the most important criteria [4, 5]. For large-scale cases with real-time constraints, swarm intelligence and evolutionary algorithms can obtain high-quality feasible solutions in very short computational time. Swarm intelligence and evolutionary algorithms are becoming more and more popular for solving large-scale scheduling and optimization problems with time constraints, including energy-efficiency scheduling in complex production.

The motivation of this review work is the green manufacturing and energy-saving awareness in production scheduling area. The design of intelligent scheduling strategies should consider energy efficiency and reducing energy consumption which is an important scheduling objective in current production scheduling area. The purpose of this study is to perform a literature review about production/shop scheduling with considering energy-efficiency objectives. It can be considered as a comprehensive reference for readers from both academia and industry. We will summarize existing achievements, analyze and discuss the current and ongoing research, and indicate some future directions, especially the swarm intelligence and evolutionary algorithms for tackling such NP-hard problems. The remainder of this paper is organized as follows. "Scope" section describes the scope of this review work. Afterwards, existing achievement is summarized and analyzed in "Classification" section. Next, detail discussion and analyzing up to date and ongoing research in the field of production/shop scheduling with energy efficiency/consumption and constraints/objectives are given in "Research trends" section. Furthermore, some future research directions are also indicated in this section. Finally, this review paper is concluded in the last section.

\section{Scope}

An indispensable part of a literature review work is the review scope and purpose. The topic of this review is production/shop scheduling with energy efficiency, consumption, or cost as constraints or objectives, given in the following: (1) the category of the shop floor, (2) model of the scheduling problems, (3) objectives (e.g., energy, completion time, machine workload, due date, and so forth), (4) research approaches (strategies) or algorithms, especially swarm intelligence and evolutionary algorithms, and (5) the aspects of energy consumption.

In some publications, energy efficiency or consumption is considered as constraints. Based on the topic and special review contents, we define the words "energy efficiency", "energy consumption", "energy cost", "production scheduling", "shop scheduling", "energy scheduling", "swarm intelligence", "evolutionary algorithm", and "meta-heuristics" as index keywords in the Web of Science database. As shown in Table 1, the energy keywords and the scheduling keywords work together to delimit the index results. In this section, we only indexed the journal articles and excluded books, theses, reports, and conference papers. The index results are shown in Table 2, including the names of journals and the number of relevant published papers in each journal is not less than 2. Hence, we only focus to analyze, discuss, and synthesize the academic journal publications, and do not consider publications with other publishing forms, since the most highquality studies are published in the form of academic journals. In addition, we include some newest publications about the reviewed topic, which are not yet included in the Web of Science database at this moment. In total, to review the literature related to the "production/shop scheduling with energy
Table 1 Keywords for database index

\begin{tabular}{lll}
\hline Energy-related keywords & Scheduling-related keywords & Intelligent strategies \\
\hline Energy efficiency & Production scheduling & Swarm intelligence \\
Energy consumption & Shop scheduling & Evolutionary algorithm \\
Energy cost & Energy scheduling & Meta-heuristics \\
\hline
\end{tabular}


Table 2 Reviewed journals and number of relevant papers

\begin{tabular}{lc}
\hline Journals' names & $\begin{array}{c}\text { Number of } \\
\text { publications }\end{array}$ \\
\hline Journal of Cleaner Production & 16 \\
International Journal of Production Research & 8 \\
CIRP Annals-Manufacturing Technology & 5 \\
IEEE Access & 4 \\
Sustainability & 4 \\
Computers \& Chemical Engineering & 3 \\
International Journal of Advanced Manufacturing Technology & 3 \\
Journal of Engineering Manufacture & 3 \\
Computers in Industry & 2 \\
IEEE Transactions on Automation Science and Engineering & 2 \\
IEEE Transactions on Industrial Informatics & 2 \\
Mathematical Problems in Engineering & 2 \\
Sensors & 2
\end{tabular}

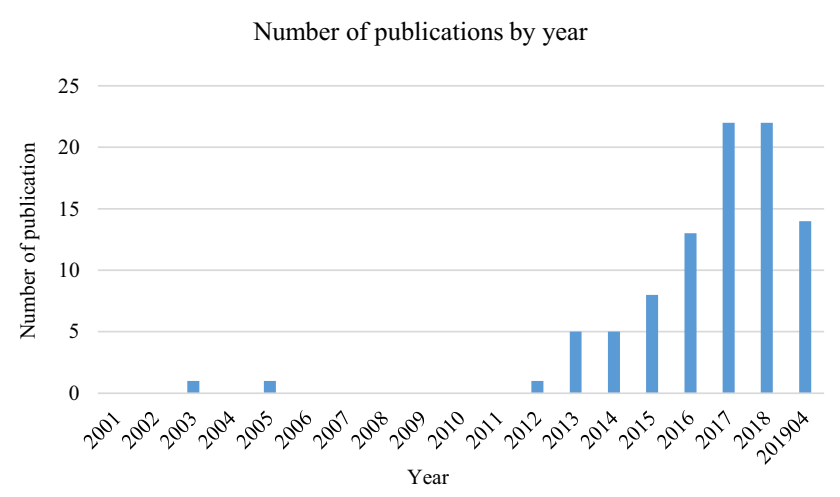

Fig. 1 Year-wise publication number addressing production scheduling with energy efficiency

efficiency or consumption as constraints or objectives" topic, 90 publications are analyzed, discussed, and synthesized till present. About 58\% of articles are published in 13 journals (i.e., one journal published at least two papers). Among these journals, the Journal of Cleaner Production published the largest number of articles (13 papers), while the International Journal of Production Research journal is placed in the second rank having 8 articles.

\section{Classification, analysis, and synthesis of existing achievements}

As shown in Fig. 1, the number of publications addressing production scheduling with energy-efficiency constraints or objectives increases rapidly since 2013 . Especially, in the first 4 months of 2019, the number of published articles is larger than half of 2018 throughout the year. These publications are classified by five criteria: shop floor category, problem model, scheduling objectives, solving approach (algorithms), and aspects of energy consumption (see Table 3).

\section{Shop floor category}

For production scheduling, shop floor category is an important issue to distinguish problem model and solving strategies. Among the articles in Table 3, job shop (including flexible job shop)-related publication accounts $41 \%$ (see Fig. 2), the ratio of flow shop related articles is about $23 \%$, and $4 \%$ publications are for single machine scheduling. Some publications do not illustrate the special shop floor category clearly and about $6 \%$ of articles addressed on a special product. Job shop scheduling and flow shop scheduling are considered as the most studied subjects, while the scheduling for a special product is rarely investigated. In fact, the energy-efficiency scheduling for a special product has more contributions and effects to the practice of scheduling theory and approaches.

\section{Problem models}

With respect to the problem model, $34 \%$ of publications developed standard mathematical program model, including integer programming (IP), integer linear programming (ILP), mixed integer linear programming (MILP), mixed integer non-linear programming (MINLP), mixed integer programming (MIP), and non-linear programming (see Fig. 3). Except standard mathematical models, some different models are used to describe energy-efficiency scheduling problems, including feedback control, neural network, decision support system, monitoring system, and time-series model. There are quite a number of articles (53\%) developed mathematical models; however, these models are not 
Table 3 Literature classification [4-6, 8-94]

\begin{tabular}{|c|c|c|c|c|c|}
\hline Articles & Shop floor category & Model & Objectives & Approach (algorithm) & $\begin{array}{l}\text { Energy consumption } \\
\text { aspect }\end{array}$ \\
\hline Lora et al., 2003 & Unknown & NLMIP & Energy & GA & Start-up and shut-down \\
\hline He et al., 2005 & Job shop & Others & $\begin{array}{l}\text { Energy and makes- } \\
\text { pan, }\end{array}$ & TS & Unknown \\
\hline Bruzzone et al., 2012 & Flexible flow shop & MIP & Energy & Heuristics & Unknown \\
\hline Cao et al., 2013 & Unknown & Neural network model & Energy & FSM & $\begin{array}{l}\text { On/off, warm up, idle, } \\
\text { and processing }\end{array}$ \\
\hline Chen et al., 2013 & Unknown & Others & Energy & Greedy algorithm & $\begin{array}{l}\text { Machine start-up/shut- } \\
\text { down }\end{array}$ \\
\hline Dai et al., 2013 & Flexible flow shop & Others & Energy and makespan & Genetic SA & Setup and idle \\
\hline Moon et al., 2013 & Unknown & MILP & Energy and makespan & Improved GA & Unknown \\
\hline Jiang et al., 2014 & Flexible job shop & Others & Energy and others & NSGAII & Processing \\
\hline Moon and Park, 2014 & Flexible job shop & MIP & Energy and others & CPLEX & $\begin{array}{l}\text { Peak load, mid-load } \\
\text { and off-peak load }\end{array}$ \\
\hline Pach et al., 2014 & FMS & Unknown & Energy and others & Unknown & Unknown \\
\hline Shrouf et al., 2014 & Single machine & Others & Energy & $\begin{array}{l}\text { GA and analytical } \\
\text { solution }\end{array}$ & Processing and Idle \\
\hline Zhang et al., 2014 & Flow shop & IP & Energy & Unknown & $\begin{array}{l}\text { peak hour, mid-peak, } \\
\text { and off peak }\end{array}$ \\
\hline Dai et al., 2015 & Job shop & MIP & Energy and makespan & Modified GA & $\begin{array}{l}\text { Loading/unloading, } \\
\text { processing }\end{array}$ \\
\hline Duerden et al., 2015 & Unknown & Others & Energy & Modified GA & Unknown \\
\hline $\begin{array}{l}\text { Garcia-Santiago et al., } \\
2015\end{array}$ & Job shop & Unknown & Energy & HS & Unknown \\
\hline Lee and Prabhu, 2015 & Unknown & Feedback control & Energy and others & $\begin{array}{l}\text { Integral controller } \\
\text { approach }\end{array}$ & Processing \\
\hline May et al., 2015 & Job shop & Others & Energy and makespan & Green GA & $\begin{array}{l}\text { Processing, idle, setup, } \\
\text { standby, and ramp }\end{array}$ \\
\hline Tang and Dai, 2015 & Job shop & MIP & Energy and makespan & Genetic SA & $\begin{array}{l}\text { Setup, processing and } \\
\text { idle }\end{array}$ \\
\hline Tong et al., 2015 & Unknown & MINLP & Energy & DICOPT & Unknown \\
\hline Zhang et al., 2015 & Multi-factories & Others & Energy & $\begin{array}{l}\text { Distributed optimiza- } \\
\text { tion }\end{array}$ & Unknown \\
\hline Escamilla et al., 2016 & Job shop & Others & Energy and makespan & GA and CPLEX & Unknown \\
\hline Li et al., 2016 & Specific product & MIP & Energy & CPLEX & Unknown \\
\hline $\begin{array}{l}\text { Oddi and Rasconi, } \\
2016\end{array}$ & Flexible job shop & Others & Energy and makespan & NLS & Unknown \\
\hline Salido et al., 2016a & Job shop & Others & Energy and others & CPLEX & Unknown \\
\hline Salido et al., 2016b & Job shop & Others & Energy and makespan & GA and CPLEX & Unknown \\
\hline Su et al., 2016 & Cracking production & MINLP & Energy and others & DICOPT & Unknown \\
\hline Tang et al., 2016 & Flexible flow shop & Others & Energy and makespan & Improved PSO & $\begin{array}{l}\text { Setup, idle and opera- } \\
\text { tion }\end{array}$ \\
\hline Tonelli et al., 2016 & Unknown & MIP & Energy and tardiness & Multi-agent & Unknown \\
\hline Tong et al., 2016 & Unknown & Others & Energy & Improved GA & Unknown \\
\hline Yan et al., 2016 & Flexible flow shop & Others & Energy and makespan & GA & Unknown \\
\hline Yang et al., 2016 & Flexible job shop & Others & Energy and makespan & NSGA-II & $\begin{array}{l}\text { Start-up, shut-down, } \\
\text { idle and processing }\end{array}$ \\
\hline $\begin{array}{l}\text { Zhang and Chiong, } \\
2016\end{array}$ & Job shop & MILP & Energy and tardiness & MOGA & $\begin{array}{l}\text { Processing and Idle } \\
\text { energy }\end{array}$ \\
\hline Giglio et al., 2017 & Job shop scheduling & MIP & Energy & $\begin{array}{l}\text { Relax-and-fix heu- } \\
\text { ristic }\end{array}$ & Setup and processing \\
\hline Gong et al., 2017 & Specific product & Others & $\begin{array}{l}\text { Energy and labor- } \\
\text { aware }\end{array}$ & GA with heuristic & Unknown \\
\hline
\end{tabular}


Table 3 (continued)

\begin{tabular}{|c|c|c|c|c|c|}
\hline Articles & Shop floor category & Model & Objectives & Approach (algorithm) & $\begin{array}{l}\text { Energy consumption } \\
\text { aspect }\end{array}$ \\
\hline Kim et al., 2017 & Unknown & Unknown & Energy & $\begin{array}{l}\text { Additive regression } \\
\text { algorithm }\end{array}$ & Unknown \\
\hline Lee et al., 2017 & Single machine & MINLP & Energy and $\mathrm{E} / \mathrm{T}$ & DIATC Heuristic & Unknown \\
\hline Lei et al., 2017 & Flexible job shop & Others & $\begin{array}{l}\text { Energy and workload } \\
\text { balance }\end{array}$ & SFLA & Unknown \\
\hline Liu et al., 2017 & Fuzzy flow shop & Others & Energy and tardiness & IGA with heuristics & $\begin{array}{l}\text { Idle, setup and process- } \\
\text { ing }\end{array}$ \\
\hline Lu et al., 2017 & Permutation flow shop & Others & Energy and makespan & HBSA & $\begin{array}{l}\text { Setup, transportation, } \\
\text { and idle }\end{array}$ \\
\hline Misra et al., 2017 & Specific product & MILP & Energy & FXOS & Unknown \\
\hline Modos et al., 2017 & Single machine & Others & Energy constraint & $\begin{array}{l}\text { Branch-and-Bound } \\
\text { and TS }\end{array}$ & Unknown \\
\hline $\begin{array}{l}\text { Mokhtari and Hasani, } \\
2017\end{array}$ & Flexible job shop & Unknown & Energy and makespan & Enhanced GA & Unknown \\
\hline $\begin{array}{l}\text { Otis and Hampson, } \\
2017\end{array}$ & Unknown & Unknown & Energy & $\begin{array}{l}\text { Advanced scheduling } \\
\text { and ERP }\end{array}$ & $\begin{array}{l}\text { Changeover and start- } \\
\text { up }\end{array}$ \\
\hline Plitsos et al., 2017 & Flexible job shop & DSS & Energy constraint & ILS & $\begin{array}{l}\text { Processing, idle, sub- } \\
\text { sidiary equipment }\end{array}$ \\
\hline $\begin{array}{l}\text { Rahimi and Ziaee, } \\
2017\end{array}$ & Permutation flow shop & Others & Energy and makespan & GA and SA & Setup and processing \\
\hline Raileanu et al., 2017 & Job shop & Others & Energy and makespan & CPLEX & Unknown \\
\hline Ramos and Leal, 2017 & Unknown & ILP & Energy & CPLEX & Unknown \\
\hline Sundstrom et al., 2017 & Unknown & MINLP & Energy and others & Systematic method & Unknown \\
\hline Wang et al., 2017 & Unknown & MINLP & Energy & DICOPT & Production \\
\hline Xu and Wang, 2017 & Job shop & Others & Energy and makespan & $\begin{array}{l}\text { feedback control } \\
\text { method }\end{array}$ & Unknown \\
\hline Yin et al., 2017 & Job shop & MIP & Energy and others & $\begin{array}{l}\text { GA with simplex lat- } \\
\text { tice design }\end{array}$ & $\begin{array}{l}\text { Loading, idle, and } \\
\text { processing }\end{array}$ \\
\hline Zhai et al., 2017 & Unknown & Time-series model & Energy & Dynamic scheduling & Unknown \\
\hline Zhang et al., 2017a & Flow shop & IP & Energy & Unknown & Unknown \\
\hline Zhang et al., 2017b & Flexible job shop & Others & Energy and makespan & $\mathrm{BBO}+\mathrm{VNS}$ & Unknown \\
\hline $\begin{array}{l}\text { Aghelinejad et al., } \\
2018\end{array}$ & Single machine & Others & Energy & GA and CPLEX & $\begin{array}{l}\text { Processing and idle } \\
\text { energy }\end{array}$ \\
\hline $\begin{array}{l}\text { Escamilla and Salido, } \\
2018\end{array}$ & Job shop & Unknown & Energy and makespan & $\mathrm{GA}+\mathrm{LS}$ & Unknown \\
\hline Feng et al., 2018 & Job shop & Monitoring system & Energy & Modified GA & Processing and idle \\
\hline Jiang and Deng 2018 & Flexible job shop & Others & Energy and $\mathrm{E} / \mathrm{T}$ & DCSO & Processing and idle \\
\hline Jiang et al., 2018a & Job shop & Others & Energy and tardiness & GWO & Idle cost and tardiness \\
\hline Jiang et al., 2018b & Job Shop & Others & $\begin{array}{l}\text { Energy and comple- } \\
\text { tion time }\end{array}$ & Improved WOA & $\begin{array}{l}\text { Machine speed, pro- } \\
\text { cessing, and idle }\end{array}$ \\
\hline $\begin{array}{l}\text { Khalaf and Wang, } \\
2018\end{array}$ & Flow shop & MILP & Energy & $\begin{array}{l}\text { General Algebraic } \\
\text { Modeling System }\end{array}$ & Unknown \\
\hline Lei et al., 2018 & Hybrid flow shop & Others & Energy and tardiness & TLBO & Unknown \\
\hline Leo and Engell, 2018 & Unknown & MILP & Energy & CPLEX & Unknown \\
\hline Li et al., 2018a & Hybrid flow shop & Others & Energy and makespan & MOA & $\begin{array}{l}\text { Processing, standby, } \\
\text { and setup }\end{array}$ \\
\hline Li et al., 2018b & Flow shop & Others & Energy and makespan & $\mathrm{ABC}$ & Unknown \\
\hline Liu et al., 2018a & Permutation flow shop & Others & Energy & NEH heuristic & Idle \\
\hline Liu et al., 2018b & Flexible flow shop & Others & Energy and makespan & Improved NSGAII & Unknown \\
\hline Lu et al., 2018 & Flow shop & Others & Energy and others & $\begin{array}{l}\text { GWA + LS Grey } \\
\text { wolf + LS }\end{array}$ & Unknown \\
\hline Meziane et al., 2018 & Flexible job shop & Others & Energy & NSGAII & Unknown \\
\hline
\end{tabular}


Table 3 (continued)

\begin{tabular}{|c|c|c|c|c|c|}
\hline Articles & Shop floor category & Model & Objectives & Approach (algorithm) & $\begin{array}{l}\text { Energy consumption } \\
\text { aspect }\end{array}$ \\
\hline Wang et al., 2018a & Blocking flow shop & Others & Energy and makespan & $\mathrm{PVNS}+\mathrm{LS}+\mathrm{NEH}$ & $\begin{array}{l}\text { Blocking and idle } \\
\text { energy }\end{array}$ \\
\hline Wang et al., 2018b & Flexible job shop & NLP & Energy and cost & $\mathrm{GA}+\mathrm{PSO}$ & Unknown \\
\hline Wu et al., 2018 & Flexible flow shop & Others & Energy and makespan & $\begin{array}{l}\text { Hybrid NSGA-II with } \\
\text { local search }\end{array}$ & Processing and Idle \\
\hline Wu and Sun, 2018 & Flexible job shop & Others & Energy and others & $\begin{array}{l}\text { NGSA_II with heu- } \\
\text { ristics }\end{array}$ & Unknown \\
\hline Zhang et al., 2018a & Flexible job shop & Others & Energy and others & IMHGA & $\begin{array}{l}\text { Processing, idle and } \\
\text { transportation }\end{array}$ \\
\hline Zhang et al., 2018b & Flexible job shop & Unknown & Energy and makespan & Modified SFLP & Unknown \\
\hline Zhao et al., 2018 & Unknown & MILP & Energy & CPLEX. & Unknown \\
\hline Cui et al., 2019 & Unknown & NLMP & Energy & Sub-gradient descent & On-peak and off-peak \\
\hline Faria et al., 2019 & Unknown & Others & Energy & GA & Unknown \\
\hline Gong et al., 2019 & Flexible job shop & Others & Energy and others & NSGA-III & $\begin{array}{l}\text { Processing, setup, } \\
\text { idling }\end{array}$ \\
\hline Gong et al., 2019 & Specific product & Others & Energy and labor & MA and NSGA-II & $\begin{array}{l}\text { Processing, setup, } \\
\text { idling }\end{array}$ \\
\hline Hassani et al., 2019 & Job shop & MILP & Energy & CPLEX & $\begin{array}{l}\text { Setup, processing, and } \\
\text { inventory }\end{array}$ \\
\hline Jiang and Wang 2019 & permutation flow shop & Others & Energy and makespan & MOEA & $\begin{array}{l}\text { Setup, processing, and } \\
\text { transportation }\end{array}$ \\
\hline $\begin{array}{l}\text { Jiang and Zhang, } \\
2019\end{array}$ & Hybrid flow shop & MILP & Energy and tardiness & EOMO algorithm & Non-processing \\
\hline Lei et al., 2019 & Flexible job shop & Others & Energy constraint & ICA & Unknown \\
\hline Liu et al., 2019 & Flexible job shop & MIP & Energy and makespan & $\mathrm{GA}+\mathrm{GSO}$ & $\begin{array}{l}\text { Processing and trans- } \\
\text { portation }\end{array}$ \\
\hline Meng et al., 2019a & Flexible job shop & MILP & Energy & CPLEX & $\begin{array}{l}\text { Idle and common } \\
\text { consumption }\end{array}$ \\
\hline Meng et al., 2019b & Hybrid flow shop & MILP & Energy & IGA & $\begin{array}{l}\text { Processing, idle, and } \\
\text { common }\end{array}$ \\
\hline Shen et al., 2019 & Unknown & Others & Energy & Improved GA & Processing and failure \\
\hline Wu et al., 2019 & Unknown & MILP & Energy & $\begin{array}{l}\text { Score ranking algo- } \\
\text { rithm }\end{array}$ & Unknown \\
\hline Zhang et al., 2019 & Flexible job shop & Others & Energy and makespan & NSGA-II & $\begin{array}{l}\text { Processing, idle, and } \\
\text { setup }\end{array}$ \\
\hline
\end{tabular}

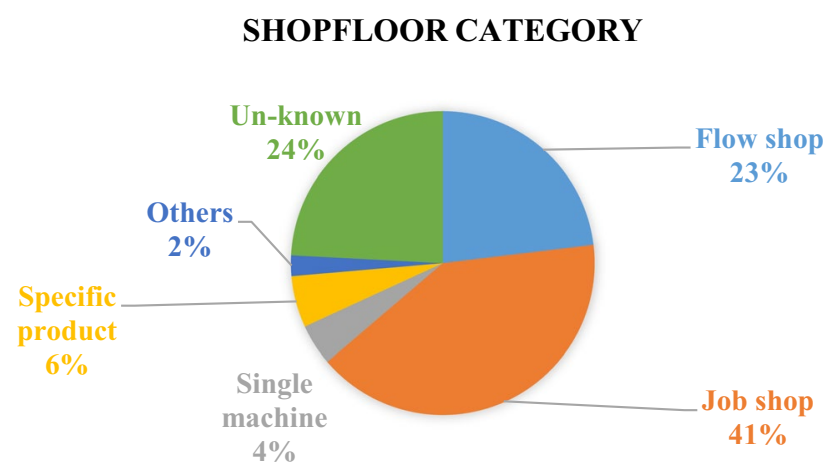

Fig. 2 Distribution of shop floor category

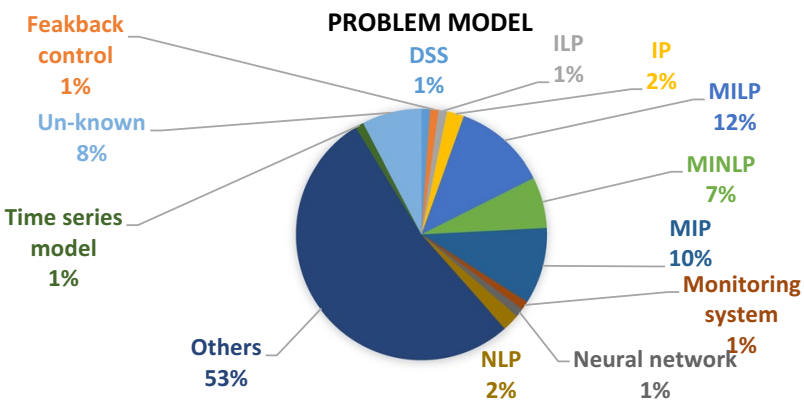

Fig. 3 Model systems

converted to standard mathematical program models or the authors did not state the model type clearly, it is categorized 
as "Others" class. We will discuss this situation in detail in the first part of next section.

\section{Swarm intelligence and evolutionary algorithms}

To solve energy-efficiency scheduling problems, many articles employed or improved swarm intelligence and evolutionary algorithms, e.g., genetic algorithm (GA), simulated annealing (SA), particle swarm optimization (PSO), shuffled frog-leaping algorithm (SFLA), grey wolf optimizer (GWO), and so forth. The detail analysis of these algorithms for energy-efficiency scheduling will be shown in part one of "Research Trend" Section. To solve energy-efficiency scheduling problem, swarm intelligence and evolutionary algorithms do not need standard mathematical models; indeed, they need mathematical formulations to compute objective functions. Among all approaches, the ratio of swarm intelligence and evolutionary algorithms is $59 \%$, which almost matches to the ratio of unstandard models (i.e., "Others" class), as shown in Fig. 3. It means that swarm intelligence and evolutionary algorithms are mainstream approaches for energy-efficiency scheduling, which has affected the problem modeling. The main procedures of swarm intelligence and evolutionary algorithms are shown as follows:

1. Initializing algorithm's parameters and the population.

2. Evaluate initializing solutions in population and objectives values.

3. Generating new solutions based on the current solutions in population.

4. Evaluate new solutions and replace the current ones.

5. If the stop criterion is not satisfied, go to Step (3); else, go to Step (6).

6. Stop and report the best solution and corresponding objective values.

For different algorithms, the strategies to generate new solutions are different, and the stop criterion is different. For different scheduling problems in intelligent production systems, there are different initializing rules and different local search operators.

To improve the convergence performance of swarm intelligence and evolutionary algorithms, some intelligent strategies are proposed in some reviewed articles. Here, we introduce several representative ones. Wu et al. [79] proposed idle time and machine turn on/off strategies for operation assignment and energy-saving purposes. Elapsed time for time turning off the idle machines is dependent on the length of idle time slots. May et al. [25] proposed an intelligent strategy to remove the overlapping solutions in the population initialization and new solutions generating phases. It can improve the diversity of population and avoid repeat solutions with the same function values. Zhang et al.
[6] developed an intelligent strategy to reduce energy consumption and improved energy efficiency in a production sequence fixed solution, by controlling the additional tardiness allowed for each job in the solution. These intelligent strategies improve the convergence performance of swarm intelligence and evolutionary algorithms, and their details can be found in the corresponding articles.

\section{Other approaches}

By observing Fig. 4, the ratio of mathematical optimization and control approach is 13\%, and the ratio of software solvers, e.g., CPLEX, DICOPT, is also $13 \%$. These two approaches need standardized mathematical models. The total ratio of these approaches $(26 \%)$ is near to the ratio of standard mathematical programming models (34\%) given in Fig. 3. In addition, $7 \%$ of articles employed heuristics to solve scheduling problems, which are also not strongly dependent on standard mathematical models of the scheduling problems. Furthermore, there are $4 \%$ articles use other approaches for solving energy-related scheduling and $4 \%$ articles do not state the applied approaches clearly.

\section{Objectives or constraints}

The objectives of energy-efficiency scheduling are distinguished as single objective and multi-objective strategies. Single objective represents only energy-related objective, including energy efficiency, energy consumption, energy cost, and so forth. Multi-objective approaches means that energy objective and traditional scheduling objectives, e.g., completion time-related objectives, machine workloadrelated objectives, due-date-related objectives and other objectives, are considered simultaneously. Based on the relationship among different objectives, multiple objectives are solved in three forms, weighted summation, non-domination, and others (normalization or as constraints). It can be seen from Fig. 5 that the total ratio of multi-objective is about $61 \%$, which is much larger than that of a single objective (36\%). It is mainstream to consider energy-related

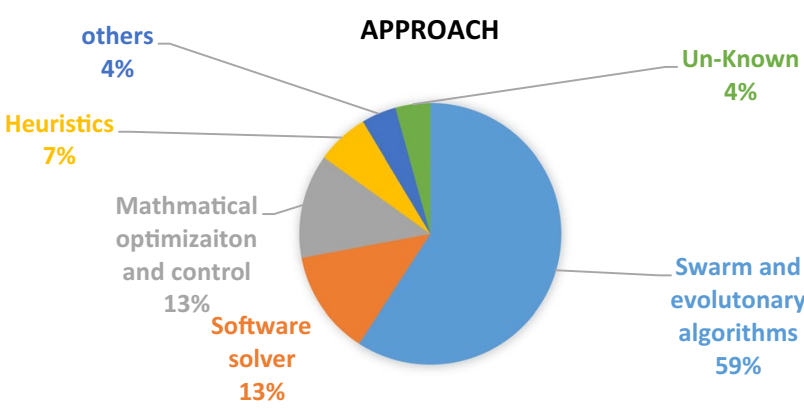

Fig. 4 Approaches and algorithms attempted 


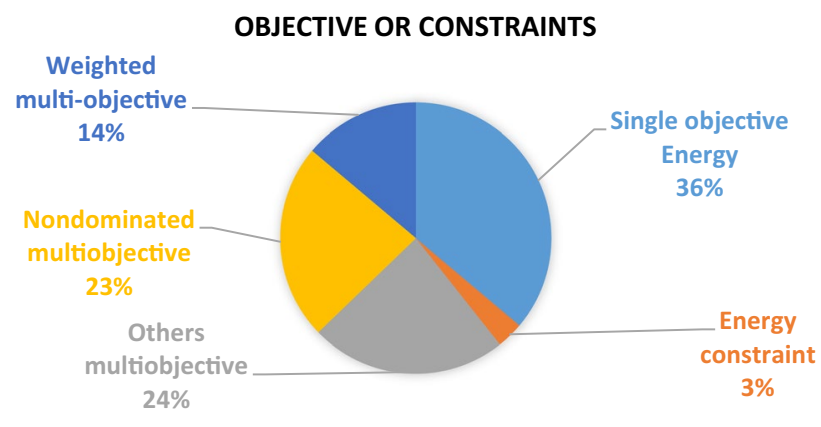

Fig. 5 Objectives systems

criteria as a single objective or one of the multiple objectives even reporting by a few articles (3\%) assuming them as scheduling constraints. To improve energy efficiency and input-output ratio, the relationship among energy-related objectives and traditional objectives must be more investigated and analyzed.

\section{Aspects of energy consumption}

To reduce energy consumption or increase energy efficiency, it is a key issue to clear the aspects of energy consumption or energy demand. Processing product, machine idle, machine setup and on/off, and product or components transportation are the aspects of energy consumption considered the most. The energy consumption in processing and machine idle is considered in more than $30 \%$ reviewed articles, and the ratio of machine setup and on/off is larger than 20\% (see Fig. 6). These three aspects of energy consumption are the mainstream of energy-efficiency scheduling. More than 50\% of publications have assumed energy efficiency as scheduling objective; however, the aspects of energy consumption or energy demand are not described clearly in these articles. Since one article may consider more than one aspects of energy consumption, the total ratio of all aspects in Fig. 6 is much larger than one.

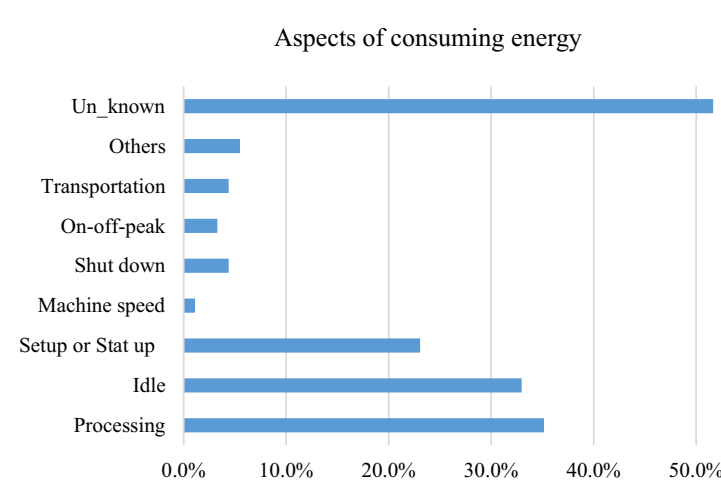

$60.0 \%$

Fig. 6 Aspects of energy consumption

\section{Research trends}

The awareness of energy efficiency, sustainability, and green manufacturing, and production scheduling with energy objectives has becomes a hot topic in the past 5 years (see Fig. 1). From 2013, the number of published articles increases year by year. The number of published articles in 2017 and 2018 is more than 20. Till April 2019, more than ten production scheduling articles for energy-related objectives are published. Energy-related objectives become a new trend of production scheduling and will play vital and important role in production scheduling.

\section{From single objective to multi-objective}

Compared to traditional scheduling objectives, energyrelated objectives are novel, however, important to economic indicators. The relationship between energy-related objectives and traditional objectives are analyzed and discussed in many publications. Many publications have considered energy-related objectives with traditional objectives simultaneously. From 2013 to April 2019, the number of articles for energy-related multi-objective scheduling is much larger than those for single energy-related objectives (see Fig. 7). It means that energy-related scheduling objectives should be considered together with traditional objectives for obtaining better decision-making by different performance indicators.

\section{Swarm intelligence and evolutionary algorithms}

With respect to approaches for solving energy-related scheduling objectives, swarm intelligence and evolutionary algorithms account 59\% among various different approaches (see Fig. 4), and all these articles are published after 2013. The GA as one of classical evolutionary algorithm and a multiobjective GA (NSGA-II) are the most employed optimizer for solving the production scheduling problems (see Fig. 8).

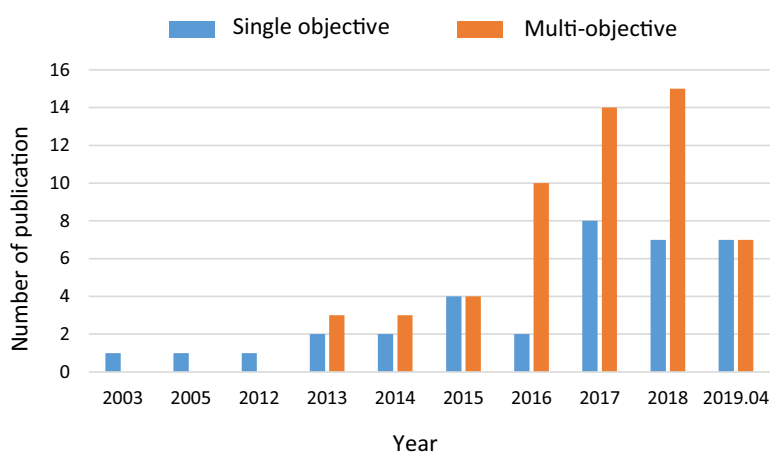

Fig. 7 Year-wise comparisons of single objective and multi-objective publications 


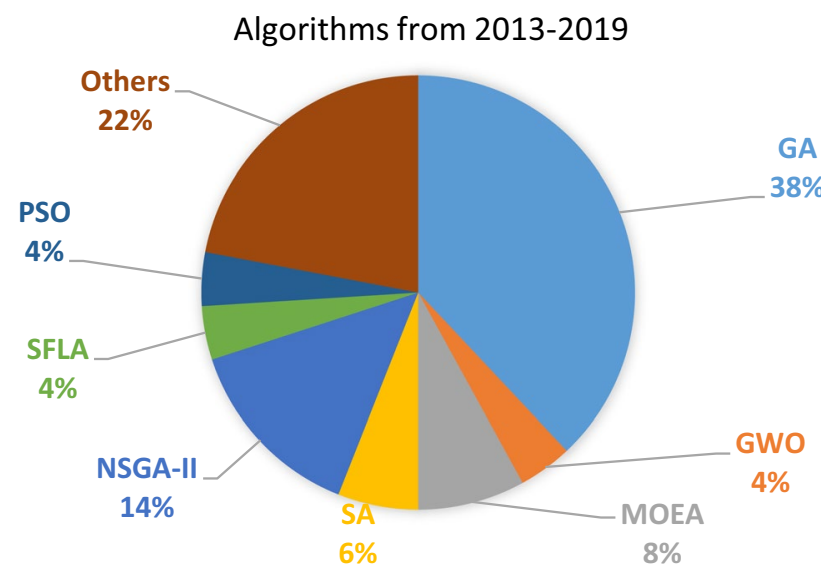

Fig. 8 Swarm and evolutionary algorithms for solving energy-related scheduling

The total ratio of GA and NSGA-II is about $52 \%$ among all swarm intelligence and evolutionary algorithms. Beside the NSGA-II, multi-objective evolutionary algorithm (MOEA) is also used in about $8 \%$ articles. The ratios of SA, PSO, shuffled frog-leaping algorithm (SFLA), and Grey wolf optimizer (GWO) are equal to or larger than $4 \%$. The algorithms with ratios less than $4 \%$ are recorded as "Others" class and the total ratio of them is $22 \%$, which means that at least six swarm intelligence and evolutionary algorithms are included in the "Others" class. Totally, more than 13 algorithms are employed or improved for solving production scheduling problems with energy-related objectives in the past 5 years. In fact, swarm intelligence and evolutionary algorithms are effective and widely used for solving energyefficiency scheduling problem.

\section{Extending of energy consumption aspects}

In the reviewed literature, the energy consumption in a production process mainly includes two parts, processing energy and non-processing energy. The non-processing energy mainly includes idle energy and setup time. From 2015 , more publications focus on these three energy consumption aspects (i.e., processing energy, idle energy, and setup energy) and the total number of articles for processing energy (i.e., 25 articles) and idle energy (i.e., 25 articles) are larger than that for setup energy (i.e., 15 articles) (seen in Fig. 9). Since energy is a non-substitutable production factor, setup energy is a necessary step for manufacturing. It is a realistic way to improve machines' efficiency, reduce processing time, and reduce the machine idle time. In addition, the transportation energy among production is considered in some publications, it is also a potential way to reduce energy consumption (see Fig. 6).

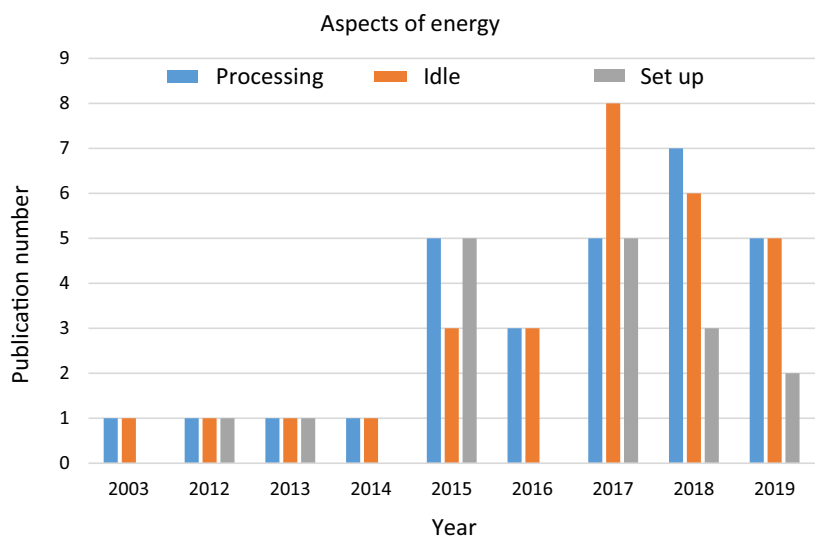

Fig. 9 Year-wise aspects of energy consumption

In summary, energy-related objectives are aware of production scheduling from 2012, especially in the past 5 years. In view of the high complexity of production scheduling, many swarm intelligence and evolutionary algorithms are employed and improved to solve this problem. Energyrelated objectives are optimized with traditional scheduling objectives, simultaneously. The main aspects of energy consumption, e.g., processing energy, idle, and setup energy, in a production process are modeled and evaluated. Some researchers have started to consider other energy consumption in a production process, for instance, energy for component transportation [80, 88].

\section{Future directions}

Based on the previous analysis of research trends of production scheduling with energy-related objectives, we consider and indicate some future research directions for this topic.

\section{Modeling of energy efficiency-related constraints and objectives}

All aspects of energy consumption in production should be classified based on necessity and possibility of reducing the cost. The aspects of energy consumption with reduction possibility should be considered and modeled as scheduling constraints or objectives in production scheduling. The more aspects of energy consumption with reduction possibility are modeled, the higher possibility to reduce energy consumption and to improve energy efficiency.

\section{Analysis of the relationship between energy-related objectives and the traditional objectives}

Production scheduling is a multi-objective problem. Energy-related objectives are emerging targets compared 
to traditional objectives, e.g., completion time, machine workload, due date, and so on, The relationship between energy-related objectives and the traditional objectives must be researched and analyzed. Does energy-related objective conflict to a certain extent with traditional objectives? It is a precondition to solve energy-efficiency scheduling and does not affect the optimization of other goals.

\section{Developing swarm intelligence and evolutionary algorithms}

Based on the synthesis and analysis in above two sections, swarm intelligence and evolutionary algorithms are efficient and effective to solve energy-efficiency scheduling problems, especially for the large-scale problems. How to design and develop more high-quality algorithms, especially nondominated multi-objective algorithms, for solving energyefficiency scheduling problem which is an important direction. Some local search operators based on the feature of energy-efficiency scheduling can conduce to improve the convergence speed of swarm intelligence and evolutionary algorithms. Algorithmic accuracy and time efficiency are the key performance indicators.

\section{Energy efficiency-based multi-objective scheduling strategy}

Energy-efficiency scheduling is an important objective in intelligent production system. There are some other objectives, e.g., completion time-related objectives, machine workload-related objectives, and the due date-related objectives and so forth. How to design energy efficiency-based multi-objective scheduling strategy is a novel and interesting direction. Especially, the non-dominate strategy for multiobjective scheduling is the key issue to improve algorithms' performance.

\section{Develop energy-efficiency intelligent scheduling framework}

Energy-efficiency scheduling is a novel topic in production scheduling. It would be a great contribution to this topic if a general framework, especially an intelligent scheduling framework, can be established, which can guide the research and development of this topic. For energy-efficiency scheduling, it would be a good way to be integrated into the overall framework of production scheduling and to be embedded into an intelligent scheduling framework with intelligent scheduling strategizes. Furthermore, the existing modeling strategies, solving approaches and algorithms (including swarm intelligence and evolutionary algorithms), and benchmark instances for general production scheduling can be directly applied to energy-efficiency scheduling or be used after appropriate adjustments.

\section{Practice in some special fields and even special products}

For production scheduling, manufacturing enterprises are more focused on the practicality of models and algorithms, especially for a special product. Till now, few published articles addressed on this matter because of since the complexity and multi-constraints in real-life situations. It is an important and practical work to model energy-efficiency scheduling for a special product and develop a high-quality meta-heuristic to solve it. This research direction can effectively promote Industry-University-Research Collaborations.

\section{Conclusions}

The growing awareness of energy efficiency and sustainable development has led to persistent attention to energy efficiency in production scheduling. The growing number of published articles, especially in the past 5 years, makes energy-efficiency scheduling a hot research topic. In the review process of this review work, there are several newest publications related to the scope of this review paper [95-99] which shows the importance and high relevancy of the studied subject. Intelligent strategies are used by many researchers in scientific community. This study presented the review of five indicators, including shop floor, models, approaches and algorithms, objectives, and aspects of energy consumption in the literature for solving energy-efficiency scheduling problems. Intelligent strategies, including swarm intelligence, evolutionary algorithms, and improvement strategies, are synthesized, discussed, and analyzed in detail. Furthermore, the current research trends, especially the intelligent strategies, are analyzed and summarized. For the continued study of this topic, five instructive directions, including modeling, objectives, intelligent strategies, intelligent scheduling framework, and practice, are given which provide an insight for future studies.

Acknowledgements This work was supported by the Faculty Research Grants (FRG) from Macau University of Science and Technology, the National Natural Science Foundation of China (Grant No. $61603169,61873328)$, the National Key R\&D Program of China (No. 2016YFB0901900), National Natural Science Fund for Distinguished Young Scholars of China (Grant No. 61525304), the DongGuan Innovative Research Team Program (No. 2018607202007), and the funding from Shandong Provincial Key Laboratory for Novel Distributed Computer Software Technology. 
Open Access This article is distributed under the terms of the Creative Commons Attribution 4.0 International License (http://creativeco mmons.org/licenses/by/4.0/), which permits unrestricted use, distribution, and reproduction in any medium, provided you give appropriate credit to the original author(s) and the source, provide a link to the Creative Commons license, and indicate if changes were made.

\section{References}

1. May G, Stahl B, Taisch M, Prabhu V (2015) Multi-objective genetic algorithm for energy-efficient job shop scheduling. Int $\mathbf{J}$ Prod Res 53(23):7071-7089

2. Key figures on Europe, statistics illustrated, 2018 edition. https ://ec.europa.eu/eurostat/documents/3217494/9309359/KS-EI18-001-EN-N.pdf/0b8d8b94-541d-4d0c-b6a4-31a1f9939a75

3. Stark AM (2019) U.S. energy use rises to highest level ever. Lawrence Livermore National Laboratory (LLNL) news release

4. Meng LL, Zhang CY, Shao XY et al (2019) MILP models for energy-aware flexible job shop scheduling problem. J Clean Prod 210:710-723

5. Meng LL, Zhang CY, Shao XY et al (2019) Mathematical modelling and optimisation of energy-conscious hybrid flow shop scheduling problem with unrelated parallel machines. Int J Prod Res 57(4):1119-1145

6. Zhang R, Chiong R (2016) Solving the energy-efficient job shop scheduling problem: a multi-objective genetic algorithm with enhanced local search for minimizing the total weighted tardiness and total energy consumption. J Clean Prod 112:3361-3375

7. Mouzon G, Yildirim MB, Twomey J (2007) Operational methods for minimization of energy consumption of manufacturing equipment. Int J Prod Res 45(18-19):4247-4271

8. Li L, Sun ZY, Yao XF, Wang DH (2016) Optimal production scheduling for energy efficiency improvement in biofuel feedstock preprocessing considering work-in-process particle separation. Energy 96:474-481

9. Lora AT, Riquelme JC, Ramos JLM, Santos JMR, Exposito AG (2003) Application of evolutionary computation techniques to the optimal short-term scheduling of the electrical energy production. Curr Top Artif Intell 3040:656-665

10. He Y, Liu F, Cao HJ, Li CB (2005) A bi-objective model for jobshop scheduling problem to minimize both energy consumption and makespan. J Cent S Univ Technol 12:167-171

11. Bruzzone AAG, Anghinolfi D, Paolucci M, Tonelli F (2012) Energy-aware scheduling for improving manufacturing process sustainability: a mathematical model for flexible flow shops. CIRP Ann-Manuf Technol 61(1):459-462

12. Cao VL, Pang CK, Gan OP et al (2013) Classification of energy consumption patterns for energy audit and machine scheduling in industrial manufacturing systems. Trans I Measure Control 35(5):583-592

13. Chen GR, Zhang L, Arinez J, Biller S (2013) Energy-efficient production systems through schedule-based operations. IEEE Trans Autom Sci Eng 10(1):27-37

14. Dai M, Tang DB, Giret A et al (2013) Energy-aware resource service scheduling based on utility evaluation in cloud manufacturing system. Proc Inst Mech Eng B J Eng Manuf 227(12):1901-1915

15. Moon JY, Shin K, Park J (2013) Optimization of production scheduling with time-dependent and machine-dependent electricity cost for industrial energy efficiency. Int J Adv Manuf Technol 68(1-4):523-535

16. Jiang ZQ, Zuo L, Mc E (2014) Study on multi-objective flexible job-shop scheduling problem considering energy consumption. J Ind Eng Manage 7(3):589-604
17. Moon JY, Park J (2014) Smart production scheduling with timedependent and machine-dependent electricity cost by considering distributed energy resources and energy storage. Int J Prod Res 52(13):3922-3939

18. Pach C, Berger T, Sallez Y et al (2014) Reactive and energyaware scheduling of flexible manufacturing systems using potential fields. Comput Ind 65(3):434-448

19. Shrouf F, Ordieres-Mere J, Garcia-Sanchez A et al (2014) Optimizing the production scheduling of a single machine to minimize total energy consumption costs. J Clean Prod 67:197-207

20. Zhang H, Zhao F, Fang K et al (2014) Energy-conscious flow shop scheduling under time-of-use electricity tariffs. CIRP Ann-Manuf Technol 63(1):37-40

21. Dai M, Tang DB, Xu YC et al (2015) Energy-aware integrated process planning and scheduling for job shops. Proc Inst Mech Eng B J Eng Manuf 229:13-26

22. Duerden CJ, Shark LK, Hall G et al (2015) Minimisation of energy consumption variance for multi-process manufacturing lines through genetic algorithm manipulation of production schedule. Eng Lett 23(1):40-48

23. Garcia-Santiago CA, Del Ser J, Upton C (2015) A random-key encoded harmony search approach for energy-efficient production scheduling with shared sources. Eng Optimiz 47(11):1481-1496

24. Lee S, Prabhu VV (2015) Energy-aware feedback control for production scheduling and capacity control. Int J Prod Res 53(23):7158-7170

25. May G, Stahl B, Taisch M et al (2015) Multi-objective genetic algorithm for energy-efficient job shop scheduling. Int J Prod Res 53(23):7071-7089

26. Tang DB, Dai M (2015) Energy-efficient approach to minimizing the energy consumption in an extended job-shop scheduling problem. Chin J Mech Eng 28(5):1048-1055

27. Tong CD, Palazoglu A, Ei-Farra NH et al (2015) Energy demand management for process systems through production scheduling and control. AIChE J 61(11):3756-3769

28. Zhang H, Zhao F, Sutherland JW (2015) Energy-efficient scheduling of multiple manufacturing factories under real-time electricity pricing. CIRP Ann-Manuf Technol 64(1):41-44

29. Joan Escamilla, Salido MA, Giret A (2016) A metaheuristic technique for energy-efficiency in job-shop scheduling. Knowl Eng Rev 31(5):475-485

30. Oddi A, Rasconi R (2016) Leveraging constraint-based approaches for multi-objective flexible flow-shop scheduling with energy costs. Intell Artif 10(2):147-160

31. Salido MA, Escamilla J, Barber F (2016) Energy efficiency, robustness, and makespan optimality in job-shop scheduling problems. AI Edam 30(3):300-312

32. Salido MA, Escamilla J, Giret A, Barber F (2016) A genetic algorithm for energy-efficiency in job-shop scheduling. Int $\mathrm{J}$ Adv Manuf Technol 85(5-8):1303-1314

33. Su LJ, Tang LX, Grossmann IE (2016) Scheduling of cracking production process with feedstocks and energy constraints. Comput Chem Eng 94:92-103

34. Tang DB, Dai M, Salido MA, Giret A (2016) Energy-efficient dynamic scheduling for a flexible flow shop using an improved particle swarm optimization. Comput Ind 81:82-95

35. Tonelli F, Bruzzone AAG, Paolucci M (2016) Assessment of mathematical programming and agent-based modelling for offline scheduling: application to energy aware manufacturing. CIRP Ann-Manuf Technol 65(1):405-408

36. Tong YF, Li JW, Li S, Li DB (2016) Research on energy-saving production scheduling based on a clustering algorithm for a forging enterprise. Sustainability 8(2):136

37. Yan JH, Li L, Zhao F (2016) A multi-level optimization approach for energy-efficient flexible flow shop scheduling. J Clean Prod 137:1543-1552 
38. Yang X, Zeng ZX, Wang RD, Sun XS (2016) Bi-objective flexible job-shop scheduling problem considering energy consumption under stochastic processing times. PLoS One 11(12):1-13

39. Giglio D, Paolucci M, Roshani A (2017) Integrated lot sizing and energy-efficient job shop scheduling problem in manufacturing/ remanufacturing systems. J Clean Prod 148:624-641

40. Gong X, Van der Wee M, De Pessemier T (2017) Integrating labor awareness to energy-efficient production scheduling under real-time electricity pricing: an empirical study. J Clean Prod 168:239-253

41. Kim SJ, Meng C, Son YJ (2017) Simulation-based machine shop operations scheduling system for energy cost reduction. Simul Model Pract Theory 77:68-83

42. Lee S, Do Chung B, Jeon HW et al (2017) A dynamic control approach for energy-efficient production scheduling on a single machine under time-varying electricity pricing. J Clean Prod 165:552-563

43. Lei DM, Zheng YL, Guo XP (2017) A shuffled frog-leaping algorithm for flexible job shop scheduling with the consideration of energy consumption. Int J Prod Res 55(11):3126-3140

44. Liu GS, Zhou Y, Yang HD (2017) Minimizing energy consumption and tardiness penalty for fuzzy flow shop scheduling with state-dependent setup time. J Clean Prod 147:470-484

45. Lu C, Gao L, Li XY et al (2017) Energy-efficient permutation flow shop scheduling problem using a hybrid multi-objective backtracking search algorithm. J Clean Prod 144:228-238

46. Misra S, Kapadi M, Gudi RD (2017) Energy-efficient production scheduling of a cryogenic air separation plant. Ind Eng Chem Res 56(15):4399-4414

47. Modos I, Sucha P, Hanzalek Z (2017) Algorithms for robust production scheduling with energy consumption limits. Comput Ind Eng 112:391-408

48. Mokhtari H, Hasani A (2017) An energy-efficient multi-objective optimization for flexibl job-shop scheduling problem. Comput Chem Eng 104:339-352

49. Otis PT, Hampson D (2017) Improve production scheduling to increase energy efficiency. Chem Eng Prog 113(3):45-51

50. Plitsos S, Repoussis PP, Mourtos I (2017) Energy-aware decision support for production scheduling. Decis Support Syst 93:88-97

51. Rahimi AR, Ziaee M (2017) Modeling and solving the permutation flow shop scheduling problem with limited buffer and the objectives of the minimization of total energy consumption and makespan. AD ALTA J Inter Res 7(1):137-148

52. Raileanu S, Anton F, Iatan A (2017) Resource scheduling based on energy consumption for sustainable manufacturing. J Intel Manuf 28(7):1519-1530

53. Ramos AG, Leal J (2017) ILP model for energy-efficient production scheduling of flake ice units in food retail stores. J Clean Prod 156:953-961

54. Sundstrom N, Wigstrom O, Lennartson B (2017) Conflict between energy, stability, and robustness in production schedules. IEEE Trans Autom Sci Eng 14(2):659-668

55. Wang XN, El-Farra NH, Palazoglu A (2017) Optimal scheduling of demand responsive industrial production with hybrid renewable energy systems. Renew Energ 100:53-64

56. Xu JJ, Wang L (2017) A feedback control method for addressing the production scheduling problem by considering energy. Sustainability 9(7):1185

57. Yin LJ, Li XY, Gao L et al (2017) Energy-efficient job shop scheduling problem with variable spindle speed using a novel multiobjective algorithm. Adv Mech Eng 9(4):1687814017695960

58. Zhai YX, Biel K, Zhao F et al (2017) Dynamic scheduling of a flow shop with on-site wind generation for energy cost reduction under real time electricity pricing. CIRP Ann-Manuf Technol 66(1):41-44
59. Zhang H, Zhao F, Sutherland JW (2017) Scheduling of a single flow shop for minimal energy cost under real-time electricity pricing. J Manuf Sci E-T ASME 139(1):14502

60. Zhang H, Dai ZW, Zhan W (2017) A new energy-aware flexible job shop scheduling method using modified biogeography-based optimization. Math Probl Eng 2017:7249876

61. Aghelinejad MM, Ouazene Y, Yalaou A (2017) Production scheduling optimisation with machine state and time-dependent energy costs. Int J Proc Res 56(16):5558-5575

62. Escamilla J, Salido MA (2018) A dual scheduling model for optimizing robustness and energy consumption in manufacturing systems. P I Mech Eng B-J Eng 232(1):5-16

63. Feng YX, Wang QR, Y Y (2018) Energy-efficient job-shop dynamic scheduling system based on the cyber-physical energymonitoring system. IEEE Access 6:52238-52247

64. Jiang TH, Deng GL (2018) Optimizing the low-carbon flexible job shop scheduling problem considering energy consumption. IEEE Access 6:46346-46355

65. Jiang TH, Zhang C, Zhu HQ et al (2018) Energy-efficient scheduling for a job shop using grey wolf optimization algorithm with double-searching mode. Math Probl Eng 2018:8574892

66. Jiang TH, Zhang C, Zhu HQ et al (2018) Energy-efficient scheduling for a job shop using an improved whale optimization algorithm. Mathematics 6(11):220

67. Khalaf AF, Wang Y (2018) Energy-cost-aware flow shop scheduling considering intermittent renewables, energy storage, and real-time electricity. Int J Energ Res 42(12):3928-3942

68. Lei DM, Gao L, Zheng YL (2018) A novel teaching-learningbased optimization algorithm for energy-efficient scheduling in hybrid flow shop. IEEE Trans Eng Manage 65(2):330-340

69. Leo E, Engell S (2018) Integrated day-ahead energy procurement and production scheduling. AT-Autom 66(11):950-963

70. Li JQ, Sang HY, Han YY et al (2018) Efficient multi-objective optimization algorithm for hybrid flow shop scheduling problems with setup energy consumptions. J Clean Prod 181:584-598

71. Li XY, Lu C, Gao L (2018) An effective multiobjective algorithm for energy-efficient scheduling in a real-Life welding shop. IEEE Trans Ind Inform 14(12):5400-5409

72. Liu GS, Li JJ, Tang YS (2018) Minimizing total idle energy consumption in the permutation flow shop scheduling problem. Asia Pac J Oper Res 35(6): 1850041

73. Liu Y, Farnsworth M, Tiwari A (2018) Energy-efficient scheduling of flexible flow shop of composite recycling. Int J Adv Manuf Technol 97(1-4):117-127

74. Lu C, Gao L, Li XY et al (2018) A multi-objective approach to welding shop scheduling for makespan, noise pollution and energy consumption. J Clean Prod 196:773-787

75. Meziane MEA, Taghezout N (2018) Predictive reactive approach for energy-aware scheduling and control of flexible manufacturing processes: application on flexible job shop. Int J Inform Syst Supply Chain Manage 11(4):43-62

76. Wang FC, Deng GL, Jiang T et al (2018) Multi-objective parallel variable neighborhood search for energy consumption scheduling in blocking flow shops. IEEE Access 6:68686-68700

77. Wang H, Jiang ZG, Wang Y et al (2018) A two-stage optimization method for energy-saving flexible job-shop scheduling based on energy dynamic characterization. J Clean Prod 188:575-588

78. Wu XL, Shen XL, Cui Q (2018) Multi-objective flexible flow shop scheduling problem considering variable processing time due to renewable energy. Sustainability 10(3):841

79. Wu XL, Sun YJ (2018) A green scheduling algorithm for flexible job shop with energy-saving measures. J Clean Prod 172:3249-3264

80. Zhang HL, Ge HJ, Pan RL et al (2018) Multi-objective bi-level programming for the energy-aware integration of flexible job shop scheduling and multi-row layout. Algorithms 11(12):210 
81. Zhang XX, Ji ZC, Wang Y (2018) An improved SFLA for flexible job shop scheduling problem considering energy consumption. Mod Phys Lett B 32(34-36):1840112

82. Zhao SN, Grossmann IE, Tang LX (2018) Integrated scheduling of rolling sector in steel production with consideration of energy consumption under time-of-use electricity prices. Comput Chem Eng 111:55-65

83. Cui WW, Li L, Lu ZQ (2019) Energy-efficient scheduling for sustainable manufacturing systems with renewable energy resources. NAV Res Log 66(2):154-173

84. Faria G, Vieira S, Costa Branco PJ (2019) Evolutionary process scheduling approach for energy cost minimization in a yeast production factory: design, simulation, and factory implementation. Energ Syst 10(1):113-139

85. Gong X, Toon DP, Luc M et al (2019) Energy- and labor-ware flexible job shop scheduling under dynamic electricity pricing: a many objective optimization investigation. J Clean Prod 209:1078-1094

86. Gong X, Liu Y, Lohse N et al (2019) energy- and labor-aware production scheduling for industrial demand response using adaptive multiobjective memetic algorithm. IEEE Trans Ind Inform 15(2):942-953

87. Hassani ZIM, El Barkany A, El Abbassi I (2019) New model of planning and scheduling for job-shop production system with energy consumption. Manag Prod Eng Rev 10(1):89-97

88. Jiang ED, Wang L (2019) An improved multi-objective evolutionary algorithm based on decomposition for energy-efficient permutation flow shop scheduling problem with sequence-dependent. Int J Prod Res 57(6): 1756-1771

89. Jiang SL, Zhang L (2019) Energy-oriented scheduling for hybrid flow shop with limited buffers through efficient multi-objective optimization. IEEE Access 7:34477-34487

90. Lei DM, Li M, Wang L (2019) A two-phase meta-heuristic for multiobjective flexible job shop scheduling problem with total energy consumption threshold. IEEE Trans Cyber 49(3):1097-1109

91. Liu ZC, Guo SS, Wang L (2019) Integrated green scheduling optimization of flexible job shop and crane transportation considering comprehensive energy consumption. J Clean Prod 211:765-786
92. Shen K, De Pessemier T, Gong X et al (2019) Genetic optimization of energy and failure aware continuous production scheduling in pasta manufacturing. Sensors 19(2):297

93. Wu ZJ, Yang KL, Yang JX et al (2019) Energy-efficiency-oriented scheduling in smart manufacturing. J Ambient Intell Hum Comput 10(3):969-978

94. Zhang ZW, Wu LH, Peng T et al (2019) An improved scheduling approach for minimizing total energy consumption and Makespan in a flexible job shop environment. Sustainability 11(1):179

95. Dai M, Tang DB, Adriana G et al (2019) Multi-objective optimization for energy-efficient flexible job shop scheduling problem with transportation constraints. Robot Comput-Integr Manuf 59:143-157

96. Zheng X, Zhou SC, Xu R et al (2019) Energy-efficient scheduling for multi-objective two-stage flow shop using a hybrid ant colony optimization algorithm. Int J Prod Res. https://doi. org/10.1080/00207543.2019.1642529

97. Fu YP, Tian GD, Fathollahi-Fard AM et al (2019) Stochastic multi-objective modelling and optimization of an energy-conscious distributed permutation flow shop scheduling problem with the total tardiness constraint. J Clean Prod 226:515-525

98. Schulz S, Neufeld JS, Buscher U (2019) A multi-objective iterated local search algorithm for comprehensive energy-aware hybrid flow shop scheduling. J Clean Prod 224:421-434

99. Tian G, Ren Y, Feng Y, Zhou MC, Zhang H, Tan J (2019) Modeling and planning for dual-objective selective disassembly using AND/OR graph and discrete artificial bee colony. IEEE Trans Ind Inform 15:2456-2468

Publisher's Note Springer Nature remains neutral with regard to jurisdictional claims in published maps and institutional affiliations. 